\title{
PERNIKAHAN DINI DAN AGENDA KEBIJAKAN KE DEPAN (KASUS DI KABUPATEN SLEMAN)
}

\author{
Muhammad Arif Fahrudin Alfana ${ }^{1}$ dan Beti Nur Hayati ${ }^{2}$
}

\begin{abstract}
This study has two main objectives. The first is to explain the condition of early marriage that occurred in Sleman District. Second, is to explain the agenda of population policy in the future to overcome the problems of early marriage that occurred. The data used is the marriage data of children in Sleman District in 2012-2015. The data is sourced from the Department of Population and Civil Registry and the Office of Religious Affairs of Sleman Regency. Data analysis was done by descriptive analysis. The results showed the number of early marriages is high. Every year, in 2013-2015, more than 100 cases of early marriage occur in Sleman. Early marriage also spread evenly across districts in Sleman District. Of all the existing sub-districts, Mlati and Ngaglik sub-districts are subdistricts that naturally or absolute have marriage cases in Sleman District. That's why some policy agenda is prepared to address the problem of early marriage. Some of these policy agendas include raising the median age of women's first marriage, lowering ASFR 15-19 and increasing enrollment rates at senior high scholl by $91.63 \%$ in 2019.
\end{abstract}

Keyword: Early Marriage, Population Policy, and Sleman District

\begin{abstract}
ABSTRAK
Penelitian ini memiliki dua tujuan menjelaskan kondisi pernikahan pada usia dini dan agenda kebijakan kependudukan ke depan untuk mengatasi permasalahan pernikahan anak di Kabupaten Sleman. Data yang digunakan adalah data pernikahan anak di Kabupaten Sleman tahun 2012-2015. Data tersebut bersumber dari Dinas Kependudukan dan Catatan Sipil dan Kantor Urusan Agama Kabupaten Sleman. Analisis data dilakukan dengan analisis deskriptif. Hasil penelitian menunjukkan bahwa jumlah pernikahan dini tergolong tinggi. Pada 2013-2015 tercatat lebih dari 100 kasus pernikahan dini terjadi setiap tahunnya. Kejadian pernikahan dini juga tersebar merata di seluruh kecamatan di Kabupaten Sleman. Dari seluruh kecamatan yang ada, Kecamatan Mlati dan Ngaglik menjadi kecamatan yang secara relatif maupun absolut memiliki kasus pernikahan tertinggi di Kabupaten Sleman Untuk itulah beberapa agenda kebijakan disiapkan untuk mengatasi permasalahan pernikahan dini. Beberapa agenda kebijakan tersebut antara lain meningkatkan median usia kawin pertama perempuan (pendewasaan usia kawin pertama), menurunkan ASFR 15-19 tahun serta meningkatkan angka partisipasi sekolah jenjang SMA/SMK/MA/sederajat pada tahun 2019 menjadi 91,63\%.
\end{abstract}

Kata Kunci: Pernikahan Dini, Kebijakan Kependudukan, dan Kabupaten Sleman

\footnotetext{
1 Dosen, Fakultas Geografi, Universitas Gadjah Mada. email: arif.fahrudinalfana@yahoo.com

2 Pembangunan Sosial dan Kesejahteraan, FISIPOL, Universitas Gadjah Mada.
} 


\section{PENDAHULUAN}

Permasalahan pernikahan dini (menikah pada usia 18 tahun ke bawah) kini menjadi perhatian serius baik pada level global, nasional maupun regional. Pada level global, berdasarkan Laporan dari Girls Not Brides, lebih dari 700 juta perempuan dan lebih dari 150 juta lakilaki berada pada kondisi pernikahan dini. Hal ini sangat menyesakkan mengingat pernikahan dini biasanya terjadi ketika usia mereka masih anak-anak yaitu dibawah 18 tahun. Jika hal ini tidak dikendalikan maka pada tahun 2050 jumlah pernikahan dini yang ada di dunia diperkirakan menjadi 1,2 milyar jiwa.

Pada level nasional, kasus pernikahan dini di Indonesia hingga saat ini masih tergolong tinggi. Kasus pernikahan dini di Indonesia sendiri tercatat berperingkat 37 di dunia dan nomor 2 di negara ASEAN. Berdasarkan data dari SDKI 2012, sebanyak 17 persen perempuan pernah kawin usia 20-24 tahun, menikah sebelum usia 18 tahun. Sementara itu berdasarkan data dari State of the World's Children UNICEF 2016, sekitar 1.408.000 perempuan Indonesia usia 20-24 menikah pada usia kurang dari 18 tahun. Berdasarkan data UNICEF tersebut dapat disimpulkan bahwa satu dari tujuh anak perempuan di Indonesia menikah sebelum usia 18 tahun.

Pada level regional, kasus pernikahan dini juga menjadi perhatian di seluruh provinsi di Indonesia. Berdasarkan Gambar 1, secara geografis, perkawinan dini terjadi di seluruh provinsi di Indonesia (BPS dan UNICEF, 2016). Rata-rata prevalensi pernikahan dini provinsi di Indonesia pada tahun 2008-2015 berada pada angka 13,3 persen sampai dengan 36,2 persen. Artinya hampir tidak ada satupun provinsi di Indonesia yang bebas dari kasus pernikahan dini.

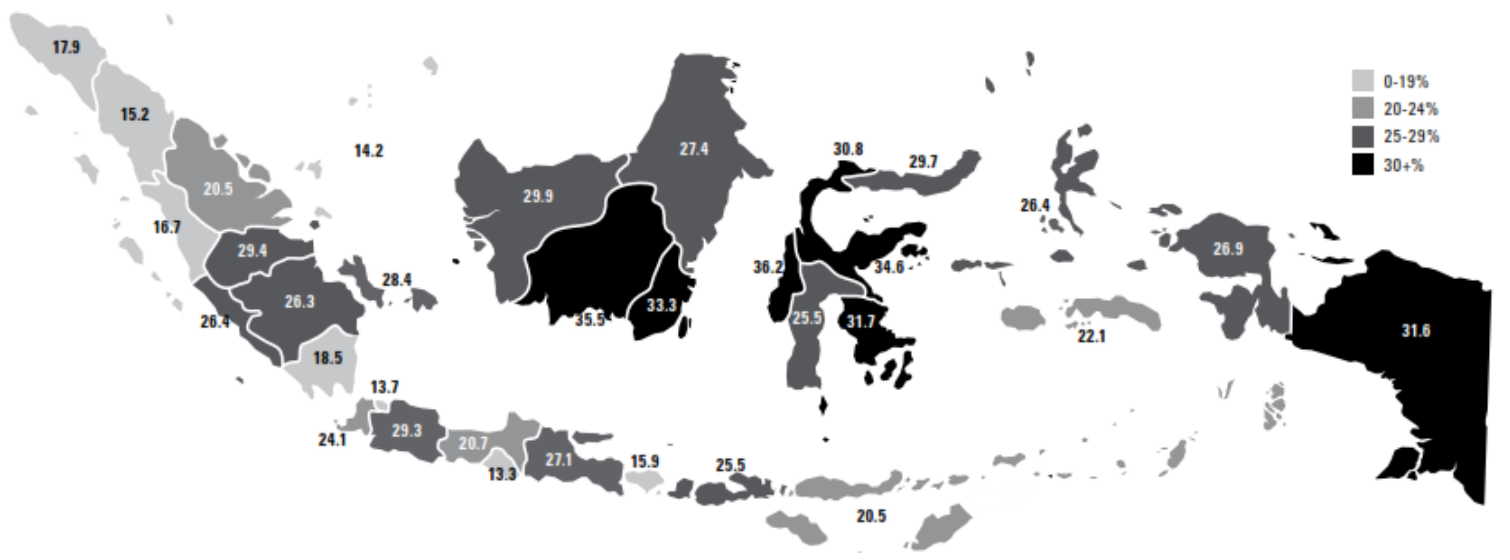

Gambar 1. Rata-rata Prevalensi Pernikahan Usia Remaja di Indonesia 2008-2015 
Data dari BPS dan UNICEF tersebut memberikan informasi bahwa Daerah Istimewa Yogyakarta (DIY) menempati peringkat terendah dalam kasus pernikahan dini. Meskipun demikian, jika dilihat dari nilai persentasenya, tetap saja nilainya masih tinggi. Rata-rata prevalensi pernikahan dini di DIY bernilai 13,3 persen. Artinya dari 10 anak yang berusia kurang dari 18 tahun, terdapat 1 anak yang telah menikah. Bahkan secara absolut, BPS (2015) menyebutkan bahwa jumlah anak yang menikah dini di DIY mencapai 13 ribu pada tahun 2015 .
Dari seluruh kabupaten dan kota yang ada di DIY, salah satu kabupaten yang mengalami permasalahan tentang pernikahan dini adalah Kabupaten Sleman. Berdasarkan data dari Dukcapil Sleman, dalam tiga tahun terakhir jumlah pasangan yang menikah dini mencapai 100 kasus ke atas (Gambar 1). Pada 2013, jumlah pasangan yang menikah pada usia dini mencapai 100 kasus. Pada tahun 2014 kasus pernikahan dini meningkat menjadi enam kali lipat menjadi 679 kasus. Sedangkan pada 2015 kasus pernikahan dini di Sleman mencapai 122 kasus.

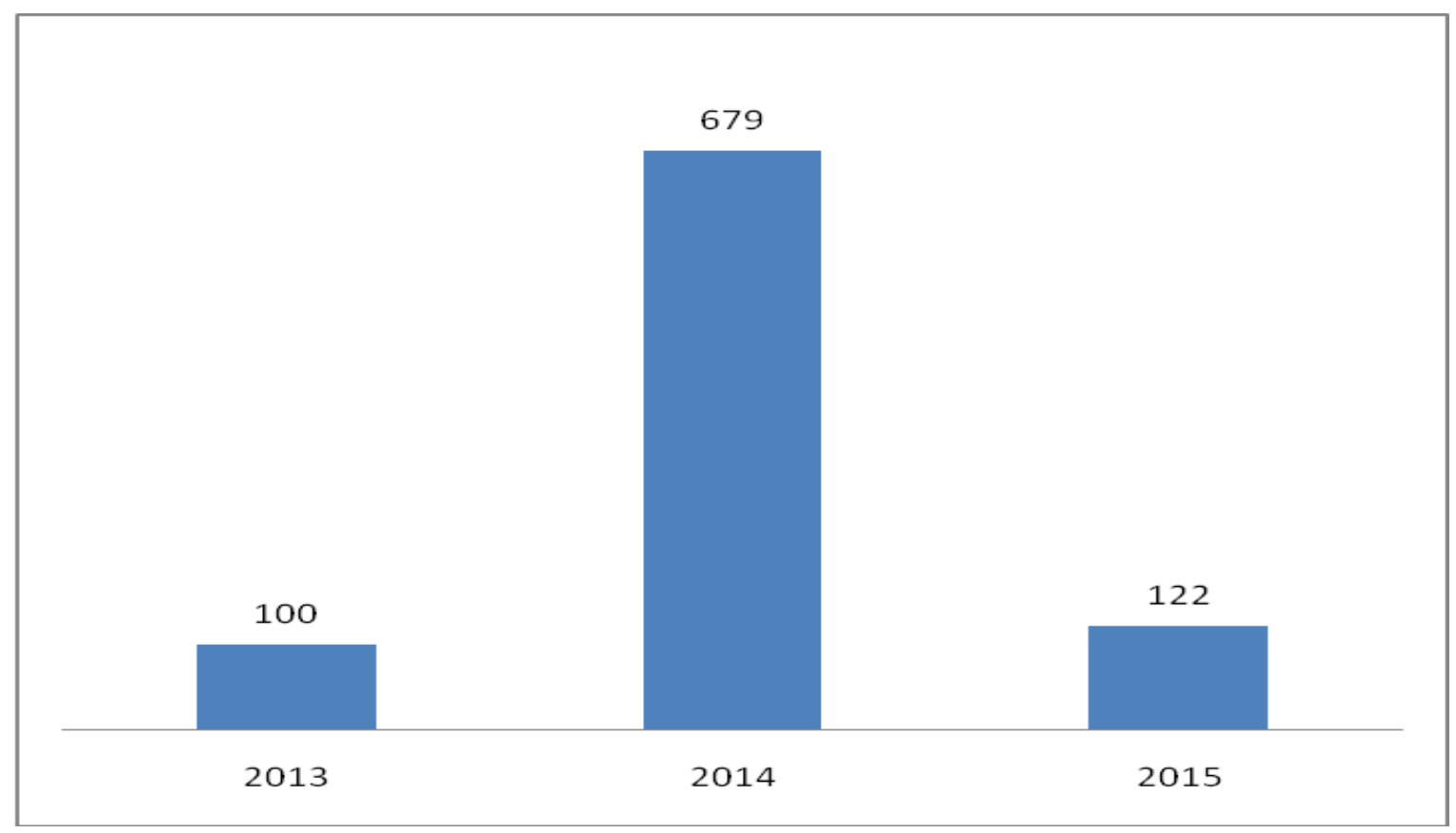

Sumber: Dukcaip Sleman (Diolah)

Gambar 2. Fluktuasi Jumlah Kasus Pernikahan Dini Kabupaten Sleman 2013-2015 
Besarnya jumlah kasus pernikahan dini di Kabupaten Sleman layak untuk dikaji. Kajian tersebut meliputi dua bagian utama. Pertama, kajian tentang bagaimana kondisi pernikahan dini di Kabupaten Sleman. Kajian kedua adalah tentang bagaimana agenda kebijakan Kabupaten Sleman ke depan dalam mengatasi permasalahan pernikahan dini ini.

\section{METODE}

Penelian ini adalah penelitian kuantitatif. Sedangkan untuk analisnya menggunakan analis yang bersifat deskriptif. Penelitian ini dilakukan di Kabupaten Sleman. Penentuan lokasi penelitian menggunakan pertimbangan daerah yang dikaji merupakan daerah dengan jumlah pernikahan dini yang tinggi di DIY. Unit analisis yang digunakan pada penelitian adalah pada level kecamatan.

Metode pengumpulan data dilakukan dengan studi kepustakaan. Metode ini merupakan suatu cara pengumpulan data yang bersumber dari penelitian-penelitian terdahulu. Data utama yang digunakan adalah data jumlah penduduk menikah menurut kelompok umur yang berasal dari Dinas
Kependudukan dan Catatan Sipil. Sedangkan data pendukung lainnya diperoleh dari laporan tahunan dari Bappeda Sleman, Publikasi capaian SDGs Sleman, beberapa jurnal serta laporan publikasi yang terkait dengan tema penelitian perkawinan dini. Data yang diperoleh akan dianaisis secara deskriptif untuk mendapatkan kesimpulan umum dari fenomena pernikahan dini di Kabupaten Sleman.

\section{HASIL DAN PEMBAHASAN}

Pada bagian ini akan membahas tiga bagian utama. Pertama akan membahas tentang urgensi penanganan pernikahan dini. Hal ini menjadi penting sebagai landasan pokok betapa agenda kebijakan penanganan pernikahan dini sangat penting bagi suatu negara, daerah maupun pada level yang lebih kecil. Kedua akan membahas spesifik tentang kondisi pernikahan dini di Kabupaten Sleman. Pembahasan bagian ini meliputi sebaran kasus pernikahan dini dan faktor yang menjadi penyebab terjadinya pernikahan dini di Kabupaten Sleman. Ketiga akan membahas agenda kebijakan ke depan dari pemerintah Kabupaten Sleman dalam menangani permasalahan pernikahan dini. 


\section{Urgensi Penanganan Pernikahan Dini}

Dalam konteks global pernikahan dini menjadi perhatian karena tingginya kasus yang terjadi. Setiap tahunnya tercatat sebanyak 15 juta wanita menikah pada usia kurang dari 18 tahun (Girls Not Brides,2015). Untuk itulah dalam kesepakatan global Sustainable Development Goals (SDGs), isu pernikahan dini termasuk dalam agenda pembangunan.

Dalam SDGs, isu pernikahan dini masuk dalam Tujuan SDGs kelima yaitu tentang Tercapainya Kesetaraan Gender dan Memberdayakan Kaum Perempuan. Target yang ditetapkan adalah menghapuskan adanya pernikahan dini pada tahun 2030. Upaya penghapusan pernikahan dini pada 2030 secara jelas tertuang dalam Target 5.3 dokumen SDGs.

Penghapusan pernikahan dini menjadi hal yang penting karena merupakan bagian yang integral untuk memberdayakan perempuan (Hanmer and Elefante, 2016). Indonesia sendiri sebagai salah satu negara yang meratifikasi SDGs harus menjalankan amanah ini. Hal ini sebagai konsekuensi agar pembangunan kependudukan di Indonesia dapat berjalan baik dan berada pada jalur yang benar. Selain itu, sebenarnya pencapaian ini juga nantinya akan melindungi warga negara Indonesia sendiri dari berbagai dampak negatif yang ditimbulkan akibat pernikahan dini.

United Nations Population Fund (2015) mengatakan bahwa pernikahan dini sangat erat dengan ketidakadilan gender, kemiskinan dan kerentanan. Selain itu pernikahan dini juga dianggap melanggar beberapa hak anak. Karena berbagai dampak negatif tersebut maka penghapusan pernikahan dini menjadi hal yang penting dan urgent untuk segera dilaksanakan. Berdasarkan BPS dan UNICEF (2016) Beberapa hak anak yang dilanggar itu antara lain:

1. Hak atas pendidikan: perkawinan usia anak akan menghalangi hak anak untuk memperoleh pendidikan, bermain, dan memenuhi potensi mereka karena dapat mengganggu atau mengakhiri pendidikan mereka

2. Hak untuk hidup bebas dari kekerasan dan pelecehan (termasuk kekerasan seksual): perkawinan usia anak meningkatkan kerentanan anak perempuan terhadap kekerasan fisik, seksual, dan mental 
3. Hak atas kesehatan : perkawinan usia anak dapat meningkatkan risiko anak perempuan terhadap penyakit dan kematian yang berhubungan dengan kehamilan dan persalinan dini. Selanjutnya, perkawinan usia anak membatasi kontrol anak perempuan atas tubuh mereka sendiri, termasuk kemampuan seksual dan reproduksi mereka

4. Hak untuk dilindungi dari eksploitasi : perkawinan usia anak seringkali terjadi tanpa persetujuan anak atau melibatkan pemaksaan yang menghasilkan keputusan yang ditujukan untuk mengambil keuntungan dari mereka atau merugikan mereka daripada memastikan bahwa kepentingan terbaik mereka terpenuhi

5. Hak untuk tidak dipisahkan dari orang tua mereka (dipisahkandari orang tua bertentangan dengan keinginan mereka) : perkawinan usia anak memisahkan anak perempuandari keluarga mereka dan menempatkan mereka dalam hubungan dan lingkungan yang asing dimana mereka mungkin tidak dirawat atau dilindungi, dan dimana mereka tidak memiliki suara atau kekuasaan dalam pengambilan keputusan atas kehidupan mereka sendiri

\section{Kasus Pernikahan Dini di Kabupaten Sleman}

Berdasarkan data dari Dukcapil Sleman jumlah pernikahan dini di Kabupaten Sleman dalam kurun waktu 2013-2015 mencapai 900 kasus. Kasus tertinggi terjadi pada tahun 2014 dengan jumlah kasus sebanyak 679 kasus. Pada 2015 menurut data dari Dukcapil, jumlah pernikahan dini di Kabupaten Sleman sebanyak 122 kasus.

Berdasarkan sumber lainnya, menurut data dari Kantor Urusan Agama (KUA), jumlah pernikahan dini yang terjadi pada kurun waktu 2013-2015 adalah sebanyak 495 kasus. Artinya, data yang di KUA jumlahnya lebih sedikit dari yag tercatat di Dukcapil Sleman. Hal ini wajar mengingat data di KUA hanya untuk pernikahan yang beragama islam. Untuk selanjutnya dalam pembahasan pada sub bab ini, data yang digunakan adalah data yang bersumber dari KUA. Data ini dipilih karena data dari KUA mampu menunjukkan sebaran kasus pernikahan dini hingga pada level kecamatan. 
Berdasarkan Tabel 1, persentase pernikahan dini di Kabupaten Sleman pada tahun 2013-2015 adalah sebesar 7,9 persen. Artinya dari 100 pernikahan sebanyak 7 atau 8 kejadian adalah pernikahan yang dilakukan pada usia dini. Jika nilai ini digunakan sebagai ambang batas, maka beberapa kecamatan yang memiliki nilai di atas itu adalah Kecamatan Godean, Minggir, Sayegan, Mlati, Prambanan, Ngemplak, Ngaglik, Pakem dan Cangkringan. Sedangkan jika dilihat berdasarkan jumlahnya, Kecamatan Mlati, Ngaglik, Gamping dan Godean menjadi kecamatan dengan

jumlah pernikahan dini terbanyak di Kabupaten Sleman.

Temuan yang menarik yang dapat dapat dilihat pada Tabel 1 adalah Kecamatan Mlati dan Ngaglik menjadi kecamatan yang baik secara absolut dan relatif menyumbang pernikahan dini terbanyak. Dua kecamatan tersebut merupakan kecamatan yang memiliki ciri-ciri daerah peralihan antara daerah kekotaan dan perdesaan. Sehingga dimungkinakan perubahan norma dan perilaku daerah transisi menjadi penyebab tingginya jumlah pernikahan dini di dua kecamatan ini.

\section{Tabel 1. Jumlah Pernikahan Dini, Jumlah Pernikahan Total dan Perbandingan Pernikahan Dini dengan Pernikahan Total}

Kabupaten Sleman 2013-2015

\begin{tabular}{|c|c|c|c|}
\hline Kecamatan & $\begin{array}{l}\text { Pernikahan Dini } \\
\text { (1) }\end{array}$ & $\begin{array}{c}\text { Pernikahan Total } \\
\text { (2) }\end{array}$ & $\begin{array}{c}\text { Persentase } \\
(1 / 2)\end{array}$ \\
\hline Gamping & 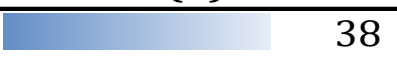 & 582 & 6,5 \\
\hline Godean & 34 & 426 & 8,0 \\
\hline Moyudan & 1. & 177 & 4,5 \\
\hline Minggir & 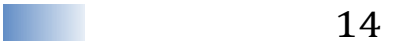 & 149 & 9,4 \\
\hline Sayegan & 32 & 336 & 9,5 \\
\hline Mlati & 48 & 552 & 8,7 \\
\hline Depok & 38 & 649 & 5,9 \\
\hline Berbah & 24 & 313 & 7,7 \\
\hline Prambanan & 34 & 354 & 9,6 \\
\hline Kalasan & 32 & 439 & 7,3 \\
\hline Ngemplak & 31 & 353 & 8,8 \\
\hline Ngaglik & 46 & 562 & 8,2 \\
\hline Sleman & 31 & 391 & 7,9 \\
\hline Tempel & 24 & 355 & 6,8 \\
\hline Turi & 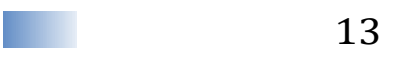 & 212 & 6,1 \\
\hline Pakem & 24 & 227 & 10,6 \\
\hline Cangkringan & 24 & 214 & 11,2 \\
\hline TOTAL & 495 & 6291 & 7,9 \\
\hline
\end{tabular}

Sumber: Data KUA se-Kabupaten Sleman, Data Diolah 2017 
Asumsi dari temuan di atas sekaligus menguatkan hasil dari penelitian sebelumnya yang membahas tentang faktor penyebab pernikahan dini di Kabupaten Sleman. Husna (2016) menyebutkan bahwa terdapat 8 faktor yang menyebabkan pernikahan dini di Sleman. Kedelapan faktor tersebut adalah disharmoni keluarga, emotional insecurity, sikap kecenderungan melakukan pergaulan bebas, kehamilan tidak dikehendaki, pendidikan ibu, tingkat sosial ekonomi, persepsi ibu, dan budaya lokal menikah dini. Dari kedelapan faktor tersebut, faktor pergaulan bebas menjadi faktor yang paling banyak mempengaruhi terjadinya pernikahan dini di Kabupaten Sleman.

Jika dilihat secara umum, kedelapan faktor yang menjadi penyebab pernikahan dini di Kabupaten Sleman juga menjadi penyebab terjadinya pernikahan dini di daerah lain. Hasil penelitian Otoo-Oyortey and Pobi (2003) menyebutkan bahwa pernikahan dini yang terjadi di Sub-Sahara Afrika disebabkan faktor kemiskinan, pendapatan rendah, pendidikan yang rendah serta aset keluarga yang terbatas. Hasil penelitian Itares (2015) di Kota Pontianak menyebutkan bahwa ada enam faktor yang menyebabkan pernikahan dini antara lain pendidikan yang rendah, tingkat ekonomi yang rendah, psikologis, budaya, lingkungan dan orang tua. Begitupula dari laporan BPS dan UNICEF (2016) yang menyatakan bahwa di Indonesia beberapa faktor yang menjadi penyebab pernikahan dini antara lain faktor lokasi yang terpencil umumnya daerah perdesaan, pendidikan yang rendah, faktor kemiskinan dan faktor budaya.

\section{Agenda Kebijakan Ke Depan}

Pernikahan dini merupakan masalah penting dalam pembangunan kependudukan. Tingginya pernikahan dini akan menghambat pencapaian isu strategis pembangunan kependudukan di Kabupaten Sleman. Isu strategis tersebut yaitu pencapaian dari aspek kualitas dan kuantitas penduduk (Alfana dan Yuanjaya, 2016). Pada aspek kuantitas tentu akan berpengaruh terhadap pengelolaan pertumbuhan penduduk. Sedangkan pada aspek kualitas akan menghambat peningkatan kualitas sumber daya manusia utamanya pada pasangan pernikahan dini dan anggota keluarganya. Oleh karena dampak yang diberikan begitu besar maka kebijakan penanganan permasalahan pernikahan dini harus dilaksanakan. 
Menurut Wessels (2009) dan Girls Not Brides (2017) pemecahan permasalahan pernikahan dini harus mempertimbangkan aspek konteks lokal wilayah. Hal ini dikarenakan permasalahan pernikahan dini sangat spesifik dan memiliki perbedaan antara satu tempat dengan tempat lainnya sehingga pemecahannya harus berpedoman pada konteks lokal dimana permasalahan itu terjadi. Cara paling sederhana adalah dengan mengidentifikasi terlebih dahulu faktor yang menyebabkan masalah tersebut terjadi. Selanjutnya dari permasalahan tersebut ditentukan agenda kebijakan yang tepat untuk mengurai dan menyelesaikan permasalahan tersebut.

Husna (2016) telah menyebutkan bahwa ada delapan faktor yang menyebabkan pernikahan dini di Kabupaten Sleman. Kedelapan faktor tersebut adalah disharmoni keluarga, emotional insecurity, sikap kecenderungan melakukan pergaulan bebas, Kehamilan Tidak Dikehendaki (KTD), pendidikan ibu, tingkat sosial ekonomi, persepsi ibu, dan budaya lokal menikah dini. Agenda kebijakan ke depan untuk meminimalkan atau menghapus pernikahan dini di
Kabupaten Sleman adalah dengan mengeliminasi faktor penyebab tersebut. Kabupaten Sleman merupakan salah satu kebupaten yang mengintegrasikan agenda pembangunan global seperti MDGs dan SDGs sebagai salah satu acuan pembangunan di daerahnya (Hayati dan Alfana, 2016). Khusus untuk integrasi SDGs, hal ini sesuai dengan Peraturan Presiden RI Nomor 59 Tahun 2017 tentang Pelaksanaan Pencapaian Tujuan Pembangunan Berkelanjutan agar daerah mengintegrasikan SDGs sebagai bagian dari agenda pembangunan di wilayahnya. Dalam dokumen SDGs tersebut beberapa sasaran ditargetkan tercapai agar pernikahan dini dapat dihapuskan. Beberapa sasaran yang harus tercapai adalah

1. Meningkatnya median usia kawin pertama perempuan (pendewasaan usia kawin pertama) pada tahun 2019 menjadi 21 tahun

2. Menurunnya ASFR 15-19 tahun pada tahun 2019 menjadi 38 tahun per 1000 kelahiran

3. Meningkatnya APK SMA/SMK/MA/sederajat pada tahun 2019 menjadi 91,63\% 
Tiga sasaran yang telah disebutkan sebelumnya harus dicapai oleh Kabupaten Sleman pada 2019. Tiga sasaran tersebut diharapkan juga mampu untuk mengeliminasi kedelapan faktor yang menjadi permasalahan pernikahan dini di Kabupaten Sleman. Selain tiga sasaran tersebut, beberapa agenda kebijakan yang dapat diadopsi dari BPS dan UNICEF (2016) dalam rangka menghapus pernikahan dini di Kabupaten Sleman antara lain menangani norma sosial dan budaya di tingkat lokal. Strategi yang dapat diterapkan adalah dengan melibatkan tokoh agama, tokoh masyarakat dan para pemangku kepentingan untuk menekan pernikahan dini. Selain itu kebijakan yang dapat diaplikasikan adalah dengan meningkatkan program kesehatan reproduksi remaja melalui advokasi dan pelayanan Komunikasi Informasi dan Edukasi (KIE). Pelaksanaannya dapat melaui terjun langsung ke sekolahsekolah atau terjun langsung ke masyarakat.

\section{SIMPULAN}

Penelitian ini telah menjelaskan bahwa pernikahan anak merupakan masalah serius yang harus segera dipecahkan karena identik dengan berbagai pelanggaran hak. Di Kabupaten Sleman sendiri, jumlah kejadian pernikahan dini tergolong tinggi. Pada 2013-2015 tercatat lebih dari 100 kasus pernikahan dini terjadi setiap tahunnya. Kejadian pernikahan dini juga tersebar merata di seluruh kecamatan di Kabupaten Sleman. Atinya tidak ada satupun kecamatan di Kabupaten Sleman yang bebas dari pernikahan dini. Dari seluruh kecamatan yang ada, Kecamatan Mlati dan Ngaglik menjadi kecamatan yang secara relatif maupun absolut memiliki kasus pernikahan tertinggi di Kabupaten Sleman.

Berdasarkan penyebabnya, ada delapan faktor yang menyebabkan pernikahan dini di Kabupaten Sleman. Kedelapan faktor tersebut adalah faktor disharmoni keluarga, emotional insecurity, sikap kecenderungan melakukan pergaulan bebas, Kehamilan Tidak Dikehendaki (KTD), pendidikan ibu, tingkat sosial ekonomi, persepsi ibu mengenai pernikahan dini, dan budaya lokal menikah dini. Dari kedelapan faktor tersebut, faktor pergaulan bebas menjadi faktor yang paling banyak mempengaruhi terjadinya pernikahan dini di Kabupaten Sleman.

Terkait agenda terhapusnya kasus pernikahan dini, hal tersebut menjadi 
tantangan pembangunan Kabupaten Sleman ke depan. Hal ini sesuai dengan agenda pembangunan global SDGs tentang target capaian penghapusan pernikahan dini pada 2030. Selaras dengan integrasi agenda SDGs, agenda kebijakan Kabupaten Sleman telah disususun untuk menanggulangi permasalahan pernikahan tersebut. Beberapa agenda kebijakan tersebut antara lain meningkatkan median usia kawin pertama perempuan (pendewasaan usia kawin pertama) pada tahun 2019 menjadi 21 tahun, ASFR 15-19 tahun pada tahun 2019 menjadi 38 tahun, serta meningkatkan APK SMA/SMK/MA/ sederajat pada tahun 2019 menjadi 91,63\%. Kebijakan lain yang dapat diterapkan adalah dengan menangani norma sosial dan budaya di tingkat lokal serta meningkatkan program kesehatan reproduksi remaja melalui advokasi dan pelayanan Komunikasi Informasi dan Edukasi (KIE). Beberapa agenda yang ditargetkan tersebut diharapkan dapat tercapai dengan cepat sehingga agenda penghapusan pernikahan dini di Kabupaten Sleman dapat terwujud bahkan sebelum tahun 2030 .

\section{PENGAKUAN DAN UCAPAN TERIMA KASIH}

Tulisan ini adalah bagian dari hasil penelitian Hibah Peningkatan Kapasitas Peneliti Dosen Muda UGM yang berjudul " Strategi Rumah Tangga Pada Pasangan Pernikahan Dini Di Kabupaten Sleman Menuju Keluarga Berkualitas" yang didanai pada tahun 2017. Penulis mengucapkan terimakasih kepada beberapa pihak diantaranya adalah Dr. Sukamdi, Dr. Agus Joko Pitoyo, Dr. Sri Rum Giyarsih dan Dr. Umi Listyaningsih atas bimbingan dan masukan yang diberikan selama penulisan. Selain itu penulis mengucapkan terimakasih kepada Nurul Husna atas share data yang diberikan.

\section{DAFTAR PUSTAKA}

Alfana, M.A.F., dan Yuanjaya, P. 2016. Pemetaan Isu Strategis Pembangunan Kependudukan di Kabupaten Sleman. dalam Seminar Nasional Pemanfaatan Informasi Geospasial untuk Peningkatan Strategi Pengelolaan Lingkungan Hidup. Prodi S2 PKLH Universitas Sebelas Maret Surakarta-Ikatan Geografi Indonesia-Kementrian Lingkungan Hidup dan KehutananBadan Informasi Geografi 2016 
Bappeda Kabupaten Sleman. 2017. Monitoring dan Evaluasi Rencana Aksi Daerah Pembangunan Kependudukan Kabupaten Sleman Tahun 2017. Sleman: Bappeda Kabupaten Sleman

ABPS. 2015. Statistik Pemuda Indonesia (Hasil Survei Sosial Ekonomi Nasional) 2015. Jakarta: Badan Pusat Statistik

BPS dan UNICEF. 2016. Kemajuan yang Tertunda: Analisis Data Perkawinan Usia Anak di Indonesia. Jakarta: Badan Pusat Statistik Indonesia

Girls Not Brides. 2016. About Child Marriage.

http://www.girlsnotbrides.org/about -child-marriage. Diakses pada 27 Februari 2017.

Girls Not Brides. 2017. Lessons Learned From National Initiatives To End Child Marriage - 2016. London: Girls Not Brides

Hanmer, L and Elefante, M. 2016. The Role of Identification in Ending Child Marriage: Identification for Development (ID4D). Washington DC: The World Bank

Hayati, B dan Alfana, M.A.F.,. 2016. Kebijakan Kependudukan di Kabupaten Sleman Pasca Berakhirnya MDGs. Natapraja. Volume 4 Nomor 2. ISSN 24069515

Husna, N. 2016. Faktor Yang Menyebabkan Terjadinya Pernikahan Dini Di Kabupaten
Sleman. Tesis. Surakarta: Program Pascasarjana Universitas Sebelas Maret

Itares, M. 2015. Fenomena Pernikahan di Usia Muda di Kecamatan Pontianak Barat Kota Pontianak. Sociologique-Jurnal Sosiologi. Volume 3 Nomor 1. Edisi Maret 2015. Universitas Tanjungpura.

Otoo-Oryortey, N. and S. Pobi. 2003. Early Marriage and Poverty: Exploring Links and Key Policy Issues. Gender and Development. Vol. 11. No. 2. 2003. pp.42-51

Pemerintah Republik Indonesia. 2017. Peraturan Presiden RI Nomor 59 Tahun 2017 tentang Pelaksanaan Pencapaian Tujuan Pembangunan Berkelanjutan. Jakarta

United Nations Population Fund. 2015. Girlhood, Not Motherhood: Preventing Adolescent Pregnancy. New York: United Nations Population Fund

UNICEF. 2016. The State of the World's Children: A Fair Chance for Every Child. New York: United Nations Children's Fund

Wessels, M. 2009. What Are We Learning About Protecting Children In The Community? An Inter-Agency Review of The Evidence on Community-Based Child Protection Mechanisms in Humanitarian. The Save the Children Fund and development settings. 